\title{
APRENDIZAGEM PARTICIPATIVA E INTERATIVA: UMA EXPERIÊNCIA NO ENSINO SUPERIOR POR MEIO DOS MÉTODOS ATIVOS
}

\author{
Silvana Neumann Martins ${ }^{1}$ \\ Natanael Pedro Castoldi ${ }^{2}$ \\ Amanda Cherini Ferraz ${ }^{3}$ \\ Liciane Diehll ${ }^{4}$ \\ Samai Serique dos Santos Silveira ${ }^{5}$
}

\begin{abstract}
Resumo: O presente artigo tem como objetivo apresentar uma pesquisa realizada na Universidade do Vale do Taquari - Univates, na cidade de Lajeado/RS, na disciplina Psicologia nas Organizações, do curso de graduação em Administração. A pesquisa buscou compreender de que forma a inserção dos métodos ativos nas aulas da referida disciplina possibilita novas práticas pedagógicas. A abordagem da pesquisa teve cunho qualitativo, utilizando a análise textual discursiva, segundo Moraes e Galiazzi (2011). Como coleta de dados, aplicou-se um questionário e obteve-se a resposta de 53 discentes, sujeitos da pesquisa. Os resultados evidenciaram que as experiências com as metodologias ativas foram positivas, pois estimularam o envolvimento, a participação e a interação dos alunos, uma vez que promoveram a conexão entre os conteúdos da aula e a própria vida concreta e subjetiva dos discentes, possibilitando novas experiências, além da sala de aula.
\end{abstract}

Palavras-chave: Ensino superior. Aprendizagem. Prática pedagógica. Métodos ativos.

\section{PARTICIPATIVE AND INTERACTIVE LEARNING: AN EXPERIMENT IN HIGHER EDUCATION THROUGH ACTIVE METHODS}

\begin{abstract}
In light of this, this article problematizes such issues and aims to understand how the use of active methods in the classes of the course Psychology in Organizations promotes new teaching practices in the undergraduate program in Business Administration. Such work has been originated in a research carried out at the Universidade do Vale do Taquari - UNIVATES, in the city of Lajeado/RS/Brazil. It is a qualitative research, with the use of discourse analysis Moraes and Galiazzi (2011). Data was provided by responses of 53 subjects (students) to a questionnaire. It has become clear that: the experiments with active methodologies were positive because they stimulated engagement, participation, and

\footnotetext{
1 Doutora em Educação pela PUC/RS. Docente permanente nos Programas de Pós-graduação em Ensino - PPGEnsino e Mestrado Profissional em Ensino de Ciências Exatas da Univates. E-mail: smartins@univates.br

2 Acadêmico do Curso de Psicologia da Univates. Bolsista de Iniciação Científica. E-mail: natanaelcastoldi@univates.br

3 Acadêmica do Curso de Psicologia da Univates. Bolsista de Iniciação Científica. E-mail: amanda.ferraz@universo.univates.br

${ }^{4}$ Doutoranda em Psicologia pela UNISINOS. Docente na Univates. E-mail: lici@univates.br

${ }^{5}$ Doutoranda no Programa de PPGEnsino - Univates. Bolsista CAPES. E-mail: sserique@hotmail.com
} 
interaction - once they linked class contents to the students' own concrete and subjective lives, promoting new experiences, and transcending the classroom.

Keywords: Higher education. Learning. Teaching practice. Active methods.

\section{Introdução}

Na busca pela compreensão das teorias do conhecimento e suas inter-relações com os processos de ensino e aprendizagem, Santos (2008a) evidencia que tais processos são fenômenos concebidos, na maioria das vezes, de forma dissociada e predominantemente fragmentária. Essa concepção dificulta ver sentido naquilo que se ensina e se aprende, uma vez que está desconexo de outros conteúdos e da realidade vivenciada. $\mathrm{O}$ autor destaca que o pensamento cartesiano ainda se faz presente nas instituições educacionais e que "[...] a fragmentação do conhecimento, que se generaliza e se reproduz por meio da organização social e educacional, tem também configurado o modo de ser e pensar dos sujeitos" (SANTOS, 2008a, p. 71).

Como princípio dessa dissociação dos conhecimentos, todas as questões de natureza complexa, segundo Descartes, devem ser simplificadas e reduzidas, fragmento por fragmento, a partículas mínimas, para a facilitação da aprendizagem. Contudo, Santos (2008a) enfatiza que esse método, ao invés de promover o conhecimento complexo, praticamente o impossibilita, e o discente, uma vez posto diante de uma matriz curricular feita em partículas, tem imensa dificuldade de conectar os elementos nela dispostos.

Nessa perspectiva, os currículos universitários tradicionais tendem a ser fragmentados e inflexíveis. Segundo Moran (2007), se não há suficiente comunicação entre as matérias que os constituem, também não há neles uma potência interna de transformação. Ocupam-se mais em responder às necessidades das universidades e dos docentes, do que às necessidades dos discentes.

Gesser e Ranghetti (2011), ao problematizarem os atuais modelos de organização curricular no ensino universitário brasileiro, questionam o caráter centralizador, repetitivo, linear e, muitas vezes, rígido, que engessa as práticas pedagógicas, tornando-as desarticuladas e inviabilizando experiências curriculares com conexões mais abertas, flexíveis e dialógicas. 
O currículo [...], em sua maioria, ainda é linearmente organizado por disciplinas nas quais o saber é transmitido de maneira fragmentada e tem influenciado de maneira sintomática a prática pedagógica dos professores, pois tendem a reproduzi-lo de maneira multifacetada, tal como foi concebido (p. 18).

Soares, Martins e Miranda (2015) evidenciam que a prática educacional das universidades reflete um modelo de sociedade ultrapassado, e o dissemina com sua base curricular fragmentária.

O conhecimento concebido somente de forma técnica e especializada, de acordo com o antigo modelo de gestão taylorista/fordista, não é mais suficiente, considerando a complexidade do mundo atual. Nesse sentido, a "[...] proposta taylorista de especialização das funções, com a consequente separação entre os setores de planejamento e execução do trabalho" (ARANHA, 1989, p. 116), não responde à vigente multiplicidade dos postos de trabalho, que demandam profissionais com maior envergadura para lidar com a incerteza, mediante a diversidade de perspectivas e possibilidades de atuação no mundo do trabalho. A demanda contemporânea é por sujeitos participativos, reflexivos, que tenham iniciativa e estejam dispostos a aprender.

Ainda segundo Soares, Martins e Miranda (2015, p. 18), "promover a formação de tais profissionais não é possível por meio do ensino transmissivo, intelectualista, centrado nas teorias e nas prescrições". Esses autores destacam que o tipo de educação que a universidade precisa propor não deve mais se ater exclusivamente à construção diretiva de conhecimentos teóricos. Mas, sim, à reflexão, à produção de atitudes, competências, valores, capacitando os estudantes para atuarem profissionalmente com as incertezas e na busca de soluções para os grandes problemas de nosso mundo.

Santos (2008a) aponta para a necessidade da compreensão da teoria da complexidade e transdisciplinaridade, de Edgar Morin (2011) e Basarab Nicolescu (1999), respectivamente, segundo a qual a realidade não é feita de fragmentos, mas de um todo complexo. O conhecimento e o domínio da realidade não podem ser alcançados, portanto, no estudo das partes dissociadas do todo, mas do entendimento de que todas as disciplinas e de que todos os conhecimentos precisam, 
necessariamente, articular-se. É pela ausência dessa articulação, estando o ensino universitário ainda preso ao dualismo cartesiano, que os discentes não entendem qual o sentido e a utilidade dos conhecimentos a eles ministrados em sala de aula (SANTOS, 2008a).

Diante disso, o discente universitário entra em conflito: por um lado, está se preparando para exercer uma atividade profissional que demandará envolvimento e disposição de energia; por outro, submetendo-se a um Ensino Superior pouco estimulante e conectado com a realidade e a necessidade de seu presente momento, vê as disciplinas do curso com desinteresse e como mera responsabilidade curricular e avaliativa. Os discentes, assim, tendem a comparecer às aulas sem motivação para aprender, preocupados apenas com a aprovação final, visando ao diploma. Isso produz um ciclo vicioso: as aulas, por serem desestimulantes, inibem os discentes e estes, por sua vez, tornam as aulas ainda menos envolventes e interessantes.

Esse cenário contrapõe a Lei de Diretrizes e Bases da Educação - LDB, № 9394/96, que, no Art. 43, destaca as finalidades da Educação Superior:

\footnotetext{
I - estimular a criação cultural e o desenvolvimento do espírito científico e do pensamento reflexivo;

II - formar diplomados nas diferentes áreas de conhecimento, aptos para a inserção em setores profissionais e para a participação no desenvolvimento da sociedade brasileira, e colaborar na sua formação contínua;

III - incentivar o trabalho de pesquisa e investigação científica, visando ao desenvolvimento da ciência e da tecnologia e da criação e difusão da cultura, e, desse modo, desenvolver o entendimento do homem e do meio em que vive;

$[\ldots]$

$\mathrm{V}$ - suscitar o desejo permanente de aperfeiçoamento cultural e profissional e possibilitar a correspondente concretização, integrando os conhecimentos que vão sendo adquiridos [...];

$\mathrm{VI}$ - estimular o conhecimento dos problemas do mundo presente, [...], prestar serviços especializados à comunidade e estabelecer com esta uma relação de reciprocidade;

$[\ldots]$
}

Atender o que prevê a LDB quanto às finalidades da Educação Superior tem sido um grande desafio para as universidades e para os docentes que visam à formação discente para além do domínio técnico de uma área específica do conhecimento. Tendo como base os princípios do paradigma da complexidade de Morin (2011), os conhecimentos ministrados nas instituições de ensino precisam se articular à vida dos 
discentes, pois fazem parte da mesma, e essa conexão é fundamental para o aprendizado de qualidade (SANTOS, 2008b).

A partir dessa compreensão, a presente pesquisa foi realizada como parte integrante de um projeto de cooperação entre docentes. O projeto iniciou no ano de 2014, com o planejamento de práticas pedagógicas que envolvessem o método ativo, e teve como objetivo produzir um novo fazer pedagógico em busca da melhoria da qualidade de ensino na Universidade do Vale do Taquari - Univates, situada na cidade de Lajeado, Rio Grande do Sul. Nesse contexto, o estudo aqui apresentado teve como objetivo compreender de que forma a inserção dos métodos ativos nas aulas da disciplina Psicologia nas Organizações possibilita novas práticas pedagógicas no curso de graduação em Administração.

\section{A Teoria Autopoiética}

Para Maturana (1997), os seres humanos podem ser incluídos naquilo que ele define como "máquinas autopoiéticas". Uma máquina autopoiética, sustenta o autor, é quando uma unidade individual detém em si mesma processos internos que a distinguem do espaço derredor, de modo que tudo o que the acontece em nível estrutural só é possível quando efetuado dentro dos limites de sua própria organização interna. Nesse sentido, "[a] organização autopoiética significa simplesmente processos concatenados de uma maneira específica tal que os processos concatenados produzem os componentes que constituem o sistema e especificam como uma unidade" (MATURANA, 1997, p. 72).

A individualidade da máquina autopoiética é delimitada pela sua própria estrutura processual autopoiética, que é autônoma, e sempre subordinará todas as mudanças à conservação de sua própria organização, ou seja, "[...] por meio da manutenção invariável de sua organização conservam ativamente uma identidade que não depende de suas interações com um observador" (MATURANA, 1997, p. 73).

Seguindo nas implicações do pensamento maturaniano, uma vez que a máquina autopoiética só pode trabalhar com as estruturas que possui a priori, todo o contato com um conhecimento que está muito além da presente capacidade do indivíduo e que não encontra sentido naquilo que ele já vive e entende, além de não ser 
assimilado, pode acabar sendo repelido (MATURANA, 1997). O mesmo efeito pode se dar, caso o contato seja ministrado de modo impositivo, agredindo a subjetividade do indivíduo.

O contrário também é verdadeiro: se o conhecimento é disponibilizado em conformidade com a unidade autopoiética do indivíduo, entra em sintonia com os seus processos internos e comunica-se com a estrutura vigente e, na relação dialética, tende a transformá-la qualitativamente, enriquecendo-a. A máquina autopoiética, tendo em vista a sua autopreservação, ou rejeitará o estímulo ou lidará com ele de modo a produzir uma síntese adaptativa (MATURANA, 1997).

Partindo dessa perspectiva, compreende-se que o discente autopoiético estará constantemente aberto a mudanças, para energia, para aquilo que converse com sua configuração. No entanto, não estará aberto para a doação de informações, ou seja, o aprendizado não pode acontecer na relação dualística entre sujeito e objeto, uma vez que, nesse sistema, não pode haver cenário independente da ação do sujeito aprendente: tudo é construção vivida e experienciada. Assim, Santos (2008b) afirma que "o conhecimento não preexiste o conhecer", assentando-se na própria ação do indivíduo no mundo, fazendo concluir que não pode haver uma cisão completa entre o conhecimento e a vida. Estar vivo é estar aprendendo.

Da mesma forma, Assmann (1998) acrescenta que a captação de imagens e estímulos do ambiente não é a base do conhecimento, mas um veículo através do qual o discente verifica aquilo que de antemão foi produzido em sua interioridade. Desse modo, torna-se mais relevante um ensino que ofereça a ele desafios acerca de elementos familiares para sua vida interna e externa, para fins de crítica das hipóteses que já estão em sua mente.

\section{Os Paradigmas da Complexidade e da Simplicidade}

A Teoria do Pensamento Complexo, formulada por Edgar Morin (2011), fundase na contraposição entre os paradigmas da complexidade e da simplicidade. $O$ Paradigma da Complexidade resulta da compreensão de que a realidade é constituída de uma totalidade múltipla, que não pode ser simplesmente reduzida e estudada em 
fragmentos, e cuja análise não pode escapar do desconhecido, do paradoxo e da contradição. O Paradigma da Simplicidade, por sua vez, emerge do interesse em reduzir a complexidade da realidade a fórmulas simples e fragmentárias, escapando das incompatibilidades e inteligibilidades. A esse respeito, Morin destaca:

\begin{abstract}
A complexidade surge, é verdade, lá onde o pensamento simplificador falha, mas ela integra em si tudo o que põe ordem, clareza, distinção, precisão no conhecimento. Enquanto $o$ pensamento simplificador desintegra a complexidade do real, o pensamento complexo integra o mais possível os modos simplificadores de pensar, mas recusa as consequências mutiladoras, redutoras, unidimensionais e finalmente ofuscantes de uma simplificação que se considera reflexo do que há de real na realidade $(2011$, p. 6$)$.
\end{abstract}

O pensamento simplificador atua em semelhança ao cartesianismo, que pretende explicar a existência na integralidade de sua extensão, partindo dos seus elementos básicos, invariavelmente obscurecendo, ou até impossibilitando, a perspectiva holística da realidade. No Paradigma da Simplicidade, o ser humano pode ser entendido apenas do ponto de vista biológico ou do ponto de vista social, quando, em verdade, ele compreende em si essas duas esferas. Daí a importância da transdisciplinaridade, uma vez que não se pode chegar à complexidade por meio de ciências isoladas (SANTOS, 2008a).

Morin (2011) ainda sustenta que muitos elementos da realidade que vemos ordenada têm o caos e a contradição como fundação. A própria vida de um organismo depende da contínua morte celular. Direcionando-se para o indivíduo, aponta para a multiplicidade de elementos e singularidades que possibilitam o ente de alegar-se um "Eu": nesse "Eu", há fatores biográficos e biológicos diversos, carregando em si um pouco das pessoas, dos cenários, dos acontecimentos e dos impulsos orgânicos nos quais e pelos quais a pessoa circula no mundo.

Assim, aproximando-se de Maturana (1997), é possível perceber a importância de fomentar-se um ensino que reconheça a estrutura própria do indivíduo em seu mundo, e que esse indivíduo possa vir a comunicar-se com a sua singularidade, sem ser repelido por portar incompatibilidade ou representar uma ameaça à identidade.

Da aproximação dos pensamentos de Maturana (1997) e de Morin (2011), podese entender que a subjetividade do discente está profundamente relacionada ao ambiente no qual vive e atua, com o qual a sua estrutura interna dialoga e se atualiza, 
carregando dentro de si um pouco de tudo aquilo que o cerca e com o que se relaciona. Nessa perspectiva, é inevitável observar que o aprendizado só pode acontecer efetivamente, para além do ato de decorar formulações técnicas para comportamentos maquínicos, quando os conhecimentos forem ministrados em uma atmosfera experiencial, comunicando-se com elementos do ambiente exterior e interior do discente.

Para esses autores, o próprio ambiente em que os processos de ensino e de aprendizagem se desenrolam carrega em si elementos capazes de direcionar as opções metodológicas: o contexto da atuação prática, da experiência, da conexão dialógica imediata entre conhecimentos teóricos e o mundo sensitivo é fonte de informações que explicita a dinâmica dos discentes, seus interesses e suas motivações.

Nessa relação, produz-se uma síntese que, por si mesma, é conhecimento, uma vez que resulta da comunicação entre os elementos abstratos e a realidade concreta e complexa dos discentes. Assim, para Assmann (1998), a ação do indivíduo no mundo não é o meio pelo qual ele adquire novos conhecimentos, mas, sim, o território em que testa e qualifica hipóteses mentais conformadas à sua estrutura interna, desenvolvendo-se dentro dos limites de sua flexibilidade estrutural. É relevante que o próprio meio seja entendido como ambiente de ensino e de aprendizagem e, desse modo, elaborado para fins de potencializar esses elementos.

Pode-se chamar de metodologias ativas esse cuidado na elaboração de estratégias que entrem em conformidade com o meio e a vida dos discentes e que atuem em conjunto com eles, inserindo a novidade a ser aprendida naquilo que já está estruturado no discente e no ambiente, de modo a haver relação dialética. Berbel (2011) define-as como um arcabouço de ferramentas que fundam o aprendizado em experiências reais ou simuladas que correspondam à prática de vida dos discentes, desenvolvidas na disposição e resolução de desafios.

Ampliando a concepção dos autores, Mitre et al. (2008) definem essas metodologias também nos termos do envolvimento emocional a que esse tipo de atividade direciona. As metodologias lidam com a integralidade do indivíduo, falando 
ao seu mundo e da sua perspectiva, fazendo da emoção potência para a autoiniciativa, para o direcionamento da vontade e para o exercício da curiosidade e da criatividade.

Quando Gardner (2007) desenvolve sua tese sobre as qualidades mentais mais importantes para a contemporaneidade e seu futuro, apontando para a relevância da capacidade de diálogo, de síntese e de comunicar as diversas áreas do conhecimento, consolida a importância de processos de ensino e de aprendizagem que promovam desafios estimulantes aos discentes. Desafios esses, que visem à iniciativa, ao esforço, à criatividade e à autonomia, mas que não carreguem um nível de complexidade que esteja muito abaixo ou muito acima das estruturas mentais do discente, fazendo-se desinteressantes. Desafios com nível de complexidade suficiente para a instigação das capacidades cognitivas da disciplina, da síntese, do diálogo e da criatividade, tendo, ainda, que atingir soluções de interesse para a vida particular e coletiva dentro dos limites éticos do meio.

\section{Metodologia}

O presente estudo foi desenvolvido sob a ótica qualitativa, que Godoy (1995) descreve como uma análise empírica do objeto de estudo em seu próprio ambiente, exigindo o contato do pesquisador diretamente com o cenário de onde os dados serão extraídos.

Esse tipo de abordagem foca-se na análise descritiva dos fenômenos, observados como parte do todo, sem direcionamentos quantitativos. E considera que o eixo fundamental é o estudo e a análise empírica, pois tais fenômenos podem ser compreendidos no contexto em que ocorrem e no qual estão inseridos.

Os dados apresentados neste estudo derivam de um projeto maior intitulado "Práticas pedagógicas inovadoras no Ensino Superior: possibilidades a partir de uma rede de cooperação", vinculado ao Programa de Melhoria da Qualidade de Ensino da Universidade do Vale do Taquari - Univates, instituição de ensino localizada na cidade de Lajeado, no Rio Grande do Sul. A partir desse programa, criou-se um fórum de discussão relativo ao projeto. Nesse fórum, os docentes de diferentes disciplinas compartilhavam as dúvidas, as inquietações e as experiências que estavam 
desenvolvendo em sala de aula mediadas pelo método ativo. Assim, apresenta-se neste artigo, a estratégia de ensino utilizada nessa disciplina durante o período da pesquisa.

Os sujeitos da pesquisa foram 53 dos 60 discentes ingressantes no primeiro semestre de 2015 (2015A), matriculados na disciplina no período noturno, os quais responderam um questionário que foi aplicado presencialmente, em sala de aula, no $10^{\circ}$ encontro da disciplina. Os discentes foram identificados como A1, A2, A3, sucessivamente. Abaixo há um quadro demonstrativo das atividades realizadas por meio do método ativo e a aplicação do questionário.

\begin{tabular}{|c|c|}
\hline Encontro & Atividade \\
\hline $1^{0}$ & $\begin{array}{l}\text { Em uma folha em branco, por meio de um esquema/desenho, expressar como é a sua } \\
\text { rotina semanal. } \\
\text { Grupos de } 6 \text { integrantes e criar uma única representação da rotina semanal (pode ser } \\
\text { a integração de todos em um ou pode ser escolhida a rotina de um dos integrantes, a } \\
\text { escolher). } \\
\text { Proposta: reflexões sobre a centralidade do trabalho em nossa vida. Qual é o meu ritmo? } \\
\text { Descanso para trabalhar ou trabalho para descansar? }\end{array}$ \\
\hline $2^{0}$ & $\begin{array}{l}\text { Concepções sobre o trabalho } \\
\text { Em grupos de } 4 \text { integrantes, com base em suas vivências e experiências, refletir sobre } \\
\text { cada uma destas concepções. Até três linhas para cada concepção. }\end{array}$ \\
\hline $3^{\circ}$ & $\begin{array}{l}\text { Filme - Terra Fria - } 2008 \text { - Charlize Theron } \\
\text { Debate no arupo relacionando ao tema dois encontros anteriores }\end{array}$ \\
\hline $4^{0}$ & $\begin{array}{l}\text { Tema: Aspectos Históricos da Psicologia nas Organizações } \\
\text { Formar grupos de } 4 \text { integrantes; } \\
\text { Com base na reportagem "Doenças mentais afetam um quinto da população } \\
\text { drabalhadora" (março/2015), elaborar um projeto social de intervenção / prevenção de } \\
\text { doenças mentais relacionadas ao trabalho, contemplando: } \\
\text { O que? Por que? Como? } \\
\text { Quando (previsão de datas/período)? Quem? } \\
\text { Quanto (\$)? } \\
\text { Apresentação ao final para a turma }\end{array}$ \\
\hline $5^{0}$ & $\begin{array}{l}\text { Atividade: } \\
\text { 1ª Fase: Escrever um artigo de opinião (a exemplo de artigo de jornal) sobre o artigo } \\
\text { científico "Trabalho significativo e felicidade humana". Individual, duas páginas (o } \\
\text { máximo). }\end{array}$ \\
\hline
\end{tabular}




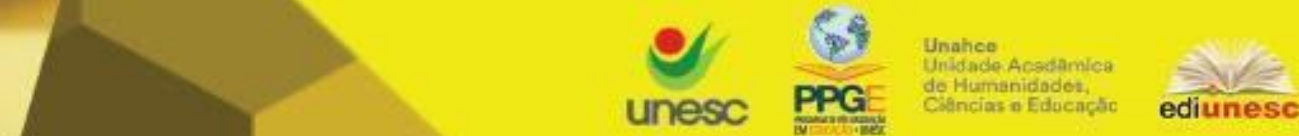

Criar Educação, Criciúma, v. 9, ํo 3, ago/dez. 2020 - PPGE - UNESC - ISSN 2317-2452

\begin{tabular}{|c|c|}
\hline & $2^{\mathrm{a}}$ fase: juntar conforme trios sorteados e integrar os artigos produzindo um. \\
\hline $6^{\circ}$ & $\begin{array}{l}\text { Seleção de foto/imagem impressa sobre o significado do trabalho em suas vidas. Refletir } \\
\text { sobre: O que as fotos têm em comum? No que se diferenciam? } \\
\text { Os significados das imagens se aproximam de que concepções do trabalho? }\end{array}$ \\
\hline $7^{0}$ & $\begin{array}{l}\text { Individualmente, ler o artigo “Trabalho imaterial e trabalho docente; } \\
\text { Técnica: World Café: formar grupos de } 5 \text { integrantes e eleger um anfitrião } \\
\text { Refletir e discutir sobre a questão: } \\
\text { Quais são as possíveis doenças relacionadas ao trabalho imaterial? } \\
\text { Fazer rodada de conhecimentos. }\end{array}$ \\
\hline $8^{\circ}$ & $\begin{array}{l}\text { Aula por meio do ensino remoto para a organização dos seminários: } \\
\text { Formar grupos de } 6 \text { integrantes; } \\
\text { Sorteio de um dos temas: } \\
\text { Estresse ocupacional } \\
\text { Síndrome de Burnout } \\
\text { Tecnoestresse } \\
\text { Transtornos mentais comuns } \\
\text { Adição ao trabalho } \\
\text { Assédio moral e assédio organizacional } \\
\text { Alcoolismo e drogas no trabalho } \\
\text { Dependência à internet } \\
\text { Absenteísmo e presentismo } \\
\text { Organizar um seminário para apresentação à turma; } \\
\text { Será avaliado o texto produzido pelo grupo. }\end{array}$ \\
\hline 9o & $\begin{array}{l}\text { Apresentação dos seminários. apresentação, conforme os critérios: } \\
\text { Criatividade (uso de diferentes técnicas, como dinâmicas de grupo, vídeos, trechos de } \\
\text { filme, testes, etc); } \\
\text { Integração entre os integrantes do grupo, de modo que a apresentação não fique } \\
\text { fragmentada; } \\
\text { Capacidade de envolver a turma que está assistindo; } \\
\text { Clareza e abordagem de todos os tópicos: Definição, Sintomas, Prevenção. } \\
\text { Que tipo de trabalhadores tende a acometer (trabalhadores de que setor/área?) }\end{array}$ \\
\hline $10^{\circ}$ & $\begin{array}{l}\text { Aplicação do questionário com as seguintes questões norteadoras: Essa técnica } \\
\text { favoreceu o seu aprendizado? Por quê? Você tem vontade de ir para essa aula? Por } \\
\text { quê? Como você se sente participando dessa aula? Como você avalia o seu grau de } \\
\text { aprendizado? }\end{array}$ \\
\hline
\end{tabular}

Fonte: elaborado pelos autores, 2020.

Como técnica de análise de dados, optou-se por uma aproximação da análise textual discursiva, que segundo Moraes (2003)

[...] pode ser compreendida como um processo auto-organizado de construção de compreensão em que novos entendimentos emergem de uma sequência recursiva de três componentes: desconstrução dos textos do corpus, a unitarização; estabelecimento de relações entre os elementos unitários, a categorização; o captar do novo emergente em que a nova compreensão é comunicada e validada (p. 192).

Assim, a análise textual discursiva parte de um ciclo de análise que inicia pela interpretação e isolamento de ideias elementares de sentido sobre o tema investigado, 
ou seja, pela unitarização, que, por sua vez, pode gerar outros conjuntos de unidades oriundas da interlocução empírica, da interlocução teórica e das interpretações feitas pelo pesquisador.

Após a realização dessa unitarização, passa-se a fazer a articulação de significados semelhantes em um processo de categorização, quando se reúnem as unidades de significado semelhantes, podendo gerar vários níveis de categorias de análise. Dessa forma, "[...] nesse processo, as categorias vão sendo aperfeiçoadas e delimitadas cada vez com maior rigor e precisão" (MORAES; GALIAZZI, 2011, p. 23). E, por último, a compreensão renovada, crítica, validação e comunicação, ou seja, "[...] a qualidade desse texto evidencia a qualidade da análise. [...]" (p. 114).

\section{Análise dos Resultados}

A partir do processo de análise, quatro categorias emergiram das unidades de significado semelhante, conforme segue: envolvimento e participação; consolidação do aprendizado; interação com a vida; crítica às metodologias ativas e tradicionais. Dessa forma, a categorização foi não apriorística, ou seja, emergiu do contexto das respostas dos sujeitos da pesquisa (CAMPOS, 2004).

\section{Envolvimento e participação}

A primeira categoria, envolvimento e participação, advém das falas dos discentes acerca de como os métodos ativos influenciaram a participação nas atividades propostas em sala de aula.

O respeito à singularidade do sujeito, constituído na complexidade de si e de seu meio, conforme estabelece Morin (2011), produziu, segundo o relato dos discentes participantes da pesquisa, um envolvimento pessoal e efetivo com os conteúdos ministrados, conforme a declaração de A26: "[...] gosto de aulas que não sejam monótonas. Como na maioria das vezes o dia de trabalho é puxado, quando as aulas são através de dinâmicas, atividades em grupos elas não se tornam cansativas". Percebe-se, nessa fala, que os afazeres diários que transcendem os estudos. Aquilo 
que atravessa o indivíduo na totalidade de sua vida interfere no seu processo de aprendizado, uma vez que absorvem seu tempo e suas energias.

O sujeito, a partir de Morin (2011), é constituído de uma miríade de fatores que se comunicam em uma totalidade, de modo que ele não pode enfatizar excessivamente um dos aspectos de sua conformação subjetiva, sem causar prejuízo noutros. Assim, a aula mediada pelos métodos ativos, uma vez que não desloca e investe apenas no aspecto intelectual e teórico do discente, pretendendo uma conexão simbiótica entre o ensino e a vida prática, mostrou-se mais atraente e dinâmica, facilitando, conforme também mencionou $A 1$, o aprendizado, que se dá na liberdade de expressão de ideias e do debate acerca delas mesmas: "[...] nessas situações em que nos comprometemos em demonstrar nossa opinião nos forçamos a prestar maior atenção e a fazer uma reflexão mais profunda sobre o assunto tratado. Também motiva saber que vou fazer parte da aula e não ser apenas um ouvinte".

Quando o discente é estimulado a pensar os conteúdos tendo em vista a sua própria vida e a expressá-los em termos pessoais, colocando muito de si na aula, diante da turma e dos conteúdos, ele tende a se ver mais profundamente implicado no próprio processo de aprendizagem, instigado, como A4, à participação: "[...] é o tipo de aula que você tem prazer em participar e que nos faz ter mais motivação para estudar e aprender".

No momento em que o discente percebe a si mesmo nos conteúdos desenvolvidos em aula e se sente desafiado a reelaborá-los, objetivando, com isso, aprimorar-se humana e profissionalmente, pode encontrar motivações para superar as próprias limitações, não somente relacionadas ao aspecto cognitivo, mas também às interações interpessoais com os demais discentes de classe. Nessa linha ponderou A7, que desafiou a sua timidez: "Fico motivada e com vontade de participar sim, mesmo sendo bastante tímida, pois acredito que isso possa me ajudar no relacionamento com o grande grupo".

Nessa perspectiva, Mitre et al. (2008) evidenciam a importância das metodologias ativas no despertamento pessoal e emocional do indivíduo, que se faz sujeito da própria aprendizagem. Segundo Soares, Martins e Miranda (2015), os discentes deixam de ser apenas agentes passivos, receptores de informações, como 
é na modalidade tradicional de ensino, para fazerem-se sujeitos ativos, que, percebendo a si mesmos nos conteúdos, encontram novos meios de aprender e de potencializar a própria vida.

Esse aspecto foi percebido por A10, que observou a dificuldade de uma aula totalmente diretiva, comparando-a com a menos diretiva: "É muito melhor uma aula diferente e aplicada. É muito chato para o discente ficar uma noite inteira ouvindo o professor falar e não interagir. Muito boa a forma da aula". Ao que A18 acrescentou a possibilidade de, em uma aula mais livre, encontrar a forma por meio da qual melhor aprende, percebendo como pode buscar seu desenvolvimento acadêmico: "Sim, pois não é uma aula onde só o professor fala, fala, fala... Eu particularmente aprendo mais fazendo do que escutando".

Conforme se observa nas falas dos discentes, a aplicação do método ativo em sala de aula estimulou envolvimento, participação e interação, uma vez que conectou os conteúdos à vida concreta e subjetiva dos discentes. É o que Mitre et al. (2008, p. 2136) evidenciam sobre o potencial dessas metodologias na mobilização das emoções e do envolvimento afetivo, ao afirmarem que "[...] a aprendizagem que envolve a autoiniciativa, alcançando as dimensões afetivas e intelectuais, torna-se mais duradoura e sólida".

\section{Consolidação do aprendizado}

A segunda categoria, consolidação do aprendizado, destaca a repercussão positiva dos métodos ativos no processo de apropriação dos conteúdos pelos discentes no desenvolvimento das aulas. Para além da participação e interação nas aulas, a aplicação do método ativo demonstrou, conforme fala dos discentes, ser eficaz na consolidação do aprendizado dos conteúdos dispostos na disciplina.

Nessa perspectiva, Berbel evidencia a importância de atividades desafiadoras e que façam sentido para a vida real dos estudantes e para o seu efetivo aprendizado.

O engajamento do aluno em relação a novas aprendizagens, pela compreensão, pela escolha e pelo interesse, é condição essencial para ampliar suas possibilidades de exercitar a liberdade e a autonomia na tomada 
de decisões em diferentes momentos do processo que vivencia, preparandose para o exercício profissional futuro. (2011, p. 29)

Os discentes sentem-se corresponsáveis na busca pelo conhecimento, e esse engajamento torna-se importante para a continuidade do trabalho a ser realizado, possibilitando o estímulo do pensamento criativo. Além de que "todo o processo desenvolvido permite tomar consciência da complexidade dos fenômenos sociais envolvidos no estudo" (BERBEL, 2011, p. 34).

Nos termos da autopoiese, Maturana (1997) explica que assimilamos em nossa estrutura aquilo que fizer sentido para o que já somos. Nessa perspectiva, A3 falou precisamente disso, demonstrando como o desafio favoreceu seu aprendizado: "Sim favoreceu [o aprendizado]. Porque é uma técnica que nos permite trabalhar mais a vontade e ao mesmo tempo faz com que vamos atrás de uma resposta, o conteúdo, o conhecimento".

A aula pautada pelo método ativo é, como bem disse $A 3$, "[...] mais livre, mais aberta". As atividades não são fechadas, não exigem apenas conhecimentos técnicos e respostas prontas, decoradas, como tende a ser o ensino tradicional, conforme Soares, Martins e Miranda (2015). Trata-se da disposição de desafios abertos, que servem como estímulo para a pesquisa e o encontro de respostas pessoais e dotadas de sentido, precisamente o que Gardner (2007) propõe para o estímulo efetivo dos estudantes. Como disse A5: "[...] a partir de uma ideia simples de trabalho conseguimos colocar em prática os conceitos aprendidos na aula além de discutirmos em grupo essas ideias, o que só amplia o nosso conhecimento".

Essa discussão de ideias em grupo, apontada por A5, foi também elencada por A8: "Sim, essa técnica favoreceu meu aprendizado porque me fez refletir, trocar experiências com os colegas, e a professora nos deixa mais à vontade para expor as ideias". O ambiente de aula, aberto ao método ativo, que pessoaliza os conteúdos para que façam sentido ao sujeito em sua complexidade e singularidade, cria um produtivo espaço de trocas, pois todos os envolvidos são colocados diante das informações formais e diante de sua própria prática de vida. São instigados por desafios e levados à expressão crítica de ideias perante os demais discentes. 
Quando as respostas não estão prontas, demandando a observação da própria vida e do arcabouço de experiências individuais, não é possível atuar como o discente cartesiano, fechado em si mesmo, suficiente com o docente e os livros teóricos (SANTOS, 2008a). O discente precisa procurar soluções, indo ao encontro dos colegas e de suas experiências reais. Essa importância do grupo na consolidação do aprendizado foi observada por muitos dos entrevistados, como A22, que passou a ver os processos de ensino e de aprendizagem como algo mais pessoal e afetivo, uma vez que aprendeu com outras pessoas, não somente por meio de teorias: "[...] trabalhos em grupo sempre são positivos, pois há troca de informações e opiniões. Essa técnica foi legal, pois cada um trouxe alguma imagem pessoal, o que acabou gerando um compartilhamento de sentimentos".

Esse aspecto pessoal e emocional que propicia a aprendizagem, como já visto em Mitre et al. (2008), nas considerações de Maturana (1997) e na sensibilidade de Morin (2011) à complexidade humana, também foi destacado como fonte de novos conhecimentos por A9: "sim, porque é mais participativa e faz descobrirmos o que os outros colegas pensam a respeito do tema. Com isso, há uma troca de ideias e juntos vamos construindo novos conceitos".

Mesmo que haja uma resistência inicial, considerando o paradigma educacional vigente, o modo como os métodos ativos arregimentam as emoções e o envolvimento pessoal, instigando a interação com o grupo para a resolução de problemas, tende a levar os discentes, como A50, a saírem de sua zona de conforto: "Num primeiro momento não [se sentiu atraído pelas metodologias ativas de ensino], pois estamos na zona de conforto, mas a partir do momento em que começamos a interagir e se mobilizar, até se torna divertido".

Nas falas dos discentes, por conseguinte, observa-se o potencial dos métodos ativos na assimilação dos conteúdos ministrados em sala de aula. Como os assuntos são abordados tendo em vista o cenário real da vida dos discentes, suscita-se maior interesse em sua elaboração e seu domínio, para melhor administrar a própria vida. Berbel (2011) aponta para essa qualidade das metodologias ativas, afirmando-as como pensadas dentro das realidades de vida dos estudantes e dos desafios que eles podem enfrentar em seu meio. 


\title{
Interação com a vida
}

A terceira categoria, interação com a vida, emana das falas dos discentes acerca de como as metodologias ativas influenciaram nas reflexões e condutas, considerando a integralidade de suas vidas, indo além da sala de aula.

Segundo Berbel, as metodologias ativas desenvolvem-se em desafios que conversam com a realidade de vida dos discentes. Assim, é natural esperar que a sua aplicação passe a interferir nas práticas de vida nas quais se inspiram:

\begin{abstract}
Podemos entender que as Metodologias Ativas baseiam-se em formas de desenvolver o processo de aprender, utilizando experiências reais ou simuladas, visando às condições de solucionar, com sucesso, desafios advindos das atividades essenciais da prática social, em diferentes contextos. (2011, p. 29)
\end{abstract}

No contexto dos questionários realizados, puderam-se obter relatos sobre essa influência, como em A11, para quem a metodologia possibilitou uma reflexão sobre sua profissão: "Sim, pois é uma técnica diferenciada porque o discente reflete sobre o trabalho que exerce dia a dia".

A20 deu ênfase à influência da metodologia aplicada em sua vida cotidiana, ao que A43 contribuiu, informando que, nas aulas, encontrou ferramentas capazes de enriquecer a sua vida pessoal e profissional:

\footnotetext{
Sim, pois as imagens nos trouxeram à tona uma intimidade maior sobre a rotina e a realidade dos colegas. Com isso foi possível fazermos uma reflexão mais minuciosa do nosso dia-a-dia. (A20)

Sim, pois cada aula vem com materiais novos que podemos utilizar em nosso dia-a-dia. (A43)
}

Verifica-se nas falas dos discentes, portanto, uma das características fundamentais das metodologias ativas, ou seja, elas se comunicam com a própria vida dos discentes, partindo da prática social. Possibilitam, assim, a reflexão sobre a prática de vida dos sujeitos que dela compartilham e na busca da compreensão dialética entre teoria e prática. 


\section{Crítica às metodologias ativas e tradicionais}

A quarta categoria, crítica às metodologias ativas e tradicionais, desenvolve-se com base nas falas dos discentes referentes às impressões mediante as metodologias ativas em comparação com os métodos tradicionais, compreendendo críticas e elogios aos diferentes métodos de ensino e aprendizagem.

Partindo dos debates em grupo, da interação e da participação, os discentes posicionaram-se quanto ao método ativo e ao tradicional. A2, ao comparar o método ativo ao tradicional, considerou mais relevante $o$ ativo: "A aula acaba se tornando mais legal, boa de trabalhar e interessante, não se torna aquela aula tradicional que é cansativa".

A3, tomando como base a experiência com a metodologia ativa, destacou que a aula expositiva não contribui suficientemente para o efetivo aprendizado, pois o conhecimento está pronto:

\footnotetext{
Prefiro uma aula como esta. Porque na minha opinião na aula expositiva o aluno relaxa em querer aprender, pois temos o conteúdo ali pronto. E este tipo de aula [participativa e colaborativa] faz com que o aluno busque o conhecimento em relação ao conteúdo, assim também acaba frisando melhor o que está sendo trabalhado.
}

No entanto, nem todos os discentes demonstraram apreço pelas metodologias ativas. Enquanto máquina autopoética Maturana (1997), o ser humano vai sendo constituído daquilo que o atravessa e, tendo o discente crescido sob o método de ensino tradicional, poderá ter dificuldade de se reconhecer numa aula mais aberta e livre, como enfatizou A15: "Prefiro uma aula mais tradicional, pois é onde me identifico mais".

Morin (2011), a partir da perspectiva da complexidade, entende que o indivíduo, feito de uma miríade de fatores ambientais e internos, adapta-se ao cenário. Tendo se desenvolvido enquanto estudante dentro do método tradicional, o discente pode ter-se acostumado com o modo diretivo de ministração das aulas, preferindo-o ao Método Ativo, como se pode perceber nas palavras de A45: "Na minha opinião, aprendo mais com o professor explicando do que fazendo trabalho em grupo". 
É interessante observar, em conformidade com aquilo que os discentes pontuaram, que as metodologias ativas suscitam algum estranhamento e produzem reflexões. Por sua própria estrutura, acabam entrando em choque com os métodos tradicionais, o que pode possibilitar uma crítica por parte dos discentes, pela via da comparação, da forma tradicional de ensino, assim como uma crítica às próprias metodologias ativas, já que o discente não está adaptado às suas exigências.

O estranhamento é natural, conforme Maturana (1997), pois todo novo elemento que entra em contato com a conformação da máquina autopoiética, que é o homem em seu meio, demanda adaptações e mudanças. Sendo a metodologia ativa aplicada de modo gradual, não impositivo, os processos autopoiéticos do ente humano tenderão a assimilar a nova dinâmica educacional.

\section{Considerações finais}

Do presente trabalho, é possível compreender, por meio da análise dos dados obtidos com a aplicação das metodologias ativas em aulas de graduação, que há, sim, uma forte demanda dos discentes para um modelo de ensino e de aprendizagem mais ativo, estimulante, envolvente, que venha conectar os conhecimentos ministrados em sala de aula à vida cotidiana, pessoal e profissional.

Reflexões que possibilitem o enriquecimento da experiência do indivíduo em seus contextos e que também propiciem uma maior aproximação entre o grupo de discentes com o docente são fundamentais. Percebe-se, nas falas coletadas, que a experiência dialética desenvolvida de modo fluido entre o grupo coeso cria um ambiente de liberdade e troca de conhecimentos e experiências que vêm suscitar reflexões, críticas e, por fim, consolidar o aprendizado.

Nesse sentido, foi possível perceber o quanto a aplicação das metodologias ativas na sala de aula de uma turma de graduação em Administração, em específico, é salutar para o cumprimento daquilo a que elas se propõem, ou seja, fomentar o 
aprendizado por meio de atividades envolventes e desafiadoras, que, conforme Berbel (2011), comuniquem-se com a vida e a experiência cotidiana dos discentes.

\section{Referências}

ARANHA, M. L. A. Filosofia da educação. 2. ed. São Paulo: Moderna, 1989.

ASSMANN, $\mathrm{H}$. Metáforas novas para reencantar a educação: epistemologia e didática. Piracicaba: Editora Unimep, 1998.

BERBEL, N. A. N. As metodologias ativas e a promoção da autonomia de estudantes. Semina: ciências sociais e humanas, jan./jun. 2011, v. 32, n. 1, p. 25-40.

BRASIL. Ministério de Educação e Cultura. Lei de Diretrizes e Bases da Educação no 9394/96, de 20 de dezembro de 1996. Estabelece as diretrizes e bases da Educação Nacional. Brasília: MEC, 1996.

GARDNER, H. Estruturas da mente: a teoria das Inteligências Múltiplas. Porto Alegre: Artmed, 2007.

GESSER, V.; RANGHETTI, D. S. O Currículo no Ensino Superior: princípios epistemológicos para um design contemporâneo. Revista e-Curriculum, ago./ 2011, v. 7, n. 2, p. 1-23. Disponível em:

$<$ https://revistas.pucsp.br/index.php/curriculum/article/view/6775/4902>. Acesso em: 15 fev. 2018.

GODOY, A. S. Introdução à pesquisa qualitativa e suas possibilidades. Revista de Administração de Empresas São Paulo, mar./abr., 1995, v. 35, n. 2, p. 57-63.

MATURANA, H.; GARCIA, F. J. V. De máquinas a seres vivos: autopoiese - a organização do vivo. Porto Alegre: Artes Médicas, 1997.

MITRE, S. M. et al. Metodologias ativas de ensino-aprendizagem na formação profissional em saúde: debates atuais. Ciência \& Saúde Coletiva, dez./2008, v. 13, p. 2133-2144. Disponível em:

<http://www.scielo.br/scielo.php?script=sci_arttext\&pid=S1413-

$81232008000900018 \&$ Ing=pt\&nrm=iso >. Acesso em: 07 jan. 2016.

MORAES, R. Uma tempestade de luz: a compreensão possibilitada pela análise textual discursiva. Ciência e educação, 2003, v. 9, n. 2, p 191-211. Disponível em: <http://www.scielo.br/pdf/ciedu/v9n2/04.pdf>. Acesso em: 20 abr. de 2018.

MORAES, R.; GALIAZZI, M. C. Análise textual discursiva. Editora Unijuí, 2011. 
MORAN, J. M. A educação que desejamos: novos desafios e como chegar lá. Campinas: Papirus, 2007.

MORIN, E. Introdução ao pensamento complexo. Porto Alegre: Sulina, 2011.

NICOLESCU, B. O manifesto da transdisciplinaridade. Tradução de Lucia Pereira de Souza. São Paulo: Triom, 1999.

SANTOS, A. Complexidade e transdisciplinaridade em educação: cinco princípios para resgatar o elo perdido. Revista brasileira de educação, jan./abr. 2008a, v. 13, n. 37, p. $71-84$.

SANTOS, B. S. Os tempos de aprender e aprender através dos tempos. In: PORTELLA, F. O.; BRIDI, F. R. S. (Orgs). Aprendizagem: tempos e espaços do aprender. Rio de Janeiro: Wak Editora, 2008b.

SOARES, S. R.; MARTINS, E. S.; MIRANDA, D. L. Problematização e produção criativa: ressignificando o ensino e a aprendizagem na universidade. In: SOARES, S. R.; MARTINS, E. S.; MIRANDA, D. L. Problematização e produção criativa, ressignificando o ensino e a aprendizagem na universidade. Salvador, Bahia: EDUNEB, 2015, p. 17-24. 